Bol. Acad. peru. leng. 53. 2012 (113-130)

\title{
MEDICINA Y DOGMATISMO EN NEGUIJÓN DE FERNANDO IWASAKI
}

\author{
MEDECINE ET DOGMATISME EN NEGUIJÓN DE \\ FERNANDO IWASAKI
}

\section{MEDICINE AND DOGMATISM IN “NEGUIJON” BY FERNANDO IWASAKI}

\author{
Bernat Castany Prado \\ Universidad de Barcelona
}

\section{Resumen:}

Este artículo estudia cómo en la novela Neguijón, del peruano ${ }^{1}$ Fernando Iwasaki, la medicina cumple la función de símbolo epistemológico mediante el cual se expresa una concepción escéptica del conocimiento. El carácter fundamentalmente especulativo e, incluso, elucubrativo de la medicina de los siglos XVI y XVII sería tanto una metáfora del dogmatismo que dominó la sociedad española e hispanoamericana a partir de la Contrarreforma como del dogmatismo que tienta al ser humano en toda época y lugar.

1 «Los sacamuelas les explicaron a sus padres cómo los dientes cuando eran muy voluminosos se tronchaban y conmovían mucho antes que los más pequeños, por causa de la escasa proporción que tenían en la base. Y como siendo más largos tenían que hacer más esfuerzo a la hora de morder, para que no se le aflojaran ni desapretaran le limaron la dentadura hasta que los dientes le quedaron más firmes y menudos. Desde entonces su boca era pasto de flemones y neguijones». (Iwasaki: 64) 


\section{Résumé:}

Cet article étude comment dans le roman Neguijón, du péruvien Fernando Iwasaki, la médicine joue le rôle de symbole épistémologique parmi lequel s'exprime une conception sceptique de la connaissance. Le caractère fondamentalement spéculative et, même élucubratif de la médicine du XVI et XVII siècles serait autant qu'une métaphore du dogmatisme qui a dominé la société espagnole et hispano-américaine à partir de la Contre-réforme comme du dogmatisme qui tente à l'être humain à toute époque et lieu.

\section{Abstract:}

This article examines how in the novel Neguijon of the Peruvian writer Fernando Iwasaki, medicine serves as an epistemological symbol through which a skeptical conception of knowledge is expressed. The basically speculative and even reflexive quality of medicine from the $16^{\text {th }}$ and $17^{\text {th }}$ centuries would be both a metaphor of dogmatism which dominated the Spanish and Hispano-American societies from the Counter-Reformation, as well as the dogmatism that tempts humans at any time and place.

\section{Palabras clave:}

Filosofía y literatura; Epistemología; Escepticismo; Fernando Iwasaki; Metáfora epistemológica.

Mots clés:

Philosophie et littérature ; Epistémologie ; Scepticisme ; Fernando Iwasaki; Métaphore épistémologique.

Key words:

Philosophy and literature; Epistemology; Skepticism; Fernando Iwasaki; epistemological Metaphor.

Fecha de recepción: $\quad 12 / 01 / 2012$

Fecha de aceptación: 26/04/2012 
https://doi.org/10.46744/bapl.201201.005

Dice el refrán: ¿Quién decidirá, si los médicos están en desacuerdo?"

G. K. Chesterton, Las paradojas de Mr. Pond

\section{Los símbolos epistemológicos en la literatura occidental}

En la novela Neguijón, del peruano Fernando Iwasaki, la medicina cumple la función de símbolo epistemológico mediante el cual el autor expresa una concepción escéptica del conocimiento. Tomo el concepto de «símbolo epistemológico» de Jaime Alazraki, quien, en La prosa narrativa de Jorge Luis Borges (1983), afirmó que muchos de los relatos de Borges podían leerse como una ficcionalización de las diversas concepciones acerca del conocimiento que los hombres han tenido a lo largo de la historia. A pesar de coincidir plenamente con las tesis de Alazraki, prefiero hablar de «símbolos cognoscitivos», antes que de «metáforas epistemológicas», ya que tanto las obras de Borges como las de Iwasaki no deben leerse de forma unívoca y mecánica, sino multívoca y ambigua, características que creo que recoge mejor el término símbolo.

Por otra parte, no debemos pensar que la epistemología o teoría del conocimiento es solo esa disciplina filosófica, cada vez más especializada y abstrusa, que solo pudo interesar a un autor como Borges, maestro del reciclaje literario de las ideas filosóficas. Claro está que no hablamos aquí de si la inducción científica produce verdadero conocimiento o de si los paradigmas científicos cambian mediante revoluciones o largas transiciones, sino, antes bien, de si los hombres pueden y deben pretender saber quiénes son, qué deben hacer o en qué consiste la belleza. Desde esta perspectiva, la epistemología o teoría del conocimiento se nos aparece como un tema literario fundamental, pues afecta a ámbitos tan cruciales para la literatura como son laidentidad, la ética o la estética.

Ciertamente, la reflexión acerca de las capacidades cognoscitivas del ser humano se trata de un tema literario propiamente moderno, ya que no será hasta el Renacimiento que entre en crisis el ingenuo dogmatismo medieval, que consideraba que el hombre conoce la 
realidad directamente, esto es, sin la intermediación distorsionadora de los sentidos, la razón o el lenguaje. Será la revolución copernicana la que, poniendo en evidencia que el movimiento de las estrellas es un efecto óptico provocado por el movimiento de la tierra, generará una crisis de confianza en la capacidad del ser humano para captar la realidad.

Cabe señalar que esta crisis de confianza cognoscitiva no solo fue provocada por la revolución copernicana, sino también por la disputa teológica entre católicos y protestantes acerca de la "regla de fe" y el criterio de interpretación de la Biblia; por la ruptura de la Ecumene medieval, precipitada por el «descubrimiento» de América; o por el desprestigio de la escolástica, que había sido el paradigma filosóficoteológico dominante durante más de mil años, y cuyo colapso dejó al mundo del pensamiento sin autoridades, sin vocabulario y sin método.

Esta crisis de confianza en las capacidades cognoscitivas del ser humano supuso un giro subjetivista en función del cual, antes detratar de conocerla realidad, los hombres tratarán de conocer las circunstancias bajo las cuales la «conocen», ya que estas podrían generar engaños cognoscitivos similares a los que el movimiento de la tierra provocó durante miles de años. Así, las reflexiones realizadas por Montaigne, en sus Ensayos, sobre la interioridad del hombre, concebida en permanente movimiento, y sobre el modo en que esta influye en nuestro conocimiento del mundo, pueden ser vistas como una aplicación del giro copernicano al ámbito de la filosofía y la literatura, en general. Los movimientos internos del ser humano -en el espacio (su cultura), en el tiempo (su edad), en el sentimiento (sus estados de ánimo), en su morfología (sus modos de percibir y de pensar)- serían el equivalente a los movimientos de la tierra, de modo que su estudio debería preceder siempre al estudio de la realidad.

Pronto la circunspección dejó paso a la desesperanza cognoscitiva, al solipsismo, en fin, pues, como diría Ortega y Gasset, la limpieza constante de las gafas de la metodología amenazó con postergar indefinidamente la tarea propiamente cognoscitiva. Este miedo o imposibilidad de conocer provocó esa «crisis pirrónica» o «escéptica» contra 
la que pensadores como Descartes reaccionaron tratando de hallar verdades indudables sobre las cuales volver a reconstruir el edificio del conocimiento.

Lo que nos interesa ahora es que en este contexto la teoría del conocimiento, en sentido lato, entró de lleno en la literatura. Ciertamente, mientras que en la época medieval no se reflexionaba acerca del conocimiento, puesto que este se daba como algo seguro, a partir del Renacimiento el hombre se preguntará constantemente si es posible saber. Tanto es así que, frente a la literatura medieval, que no deja de ser una constante reformulación de la revelación bíblica, la literatura moderna se nos presenta, según la feliz expresión de Octavio Paz, como una «revelación de una no revelación», esto es, como un darnos cuenta de que no conocemos.

Ciertamente, los autores literarios no reflexionarán acerca del conocimiento utilizando una terminología y un estilo especializados, sino mediante lo que hemos dado en llamar, con Alazraki, «símbolos epistemológicos». Tal es el caso, por ejemplo, del Quijote, de Cervantes, que podemos ver como «una parodia del dogmático», al que se presenta como un «loco» que ve las ideas que pueblan su mente antes que las realidades que le muestran sus sentidos, y que sufre un largo proceso de autoconocimiento a lo largo del cual aprenderá a ser más prudente y circunspecto a la hora de tratar con las apariencias así como a ser menos dogmático (Ihrie, 1982: 79).

Tal es el caso también de Othello, de Shakespeare, donde los celos dan lugar a «una crisis de confianza epistemológica» (Bell, 2002: 21) que lleva al protagonista, símbolo del dogmático que necesita certezas absolutas, a dudar de todo. Es probable que Shakespeare tomase este tema de los Ensayos de Montaigne, que conoció por la traducción de John Florio, donde se recomienda también una actitud escéptica, una santa ignorancia, y se pone como ejemplo a los romanos, que cuando volvían de un viaje enviaban a un mensajero para que avisase a su mujer que pronto estarían en casa, no deseaban más de lo que convenía a su tranquilidad. Cervantes también utilizará el símbolo epistemológico de los 
celos en «El curioso impertinente», una de las novelas intercaladas en el Quijote, donde la curiosidad malsana del protagonista le lleva a perder a su amada.

También nos encontramos con metáforas epistemológicas en $L a$ vida es sueño, de Calderón, el Primero sueño, de Sor Juana Inés de la Cruz, el Criticón de Gracián, los Sueños de Quevedo (cuyo primer título fue Que nada se sabe) y buena parte de las obras de Quevedo, Voltaire, Stevenson, Machado de Assis, Chesterton o Borges.

Detengámonos brevemente en el caso de Borges, por ser su obra una verdadera enciclopedia de símbolos epistemológicos. En la obra del autor de Ficciones, marcada según él mismo confiesa en el epílogo de Otras inquisiciones por un «escepticismo esencial» (Borges, 1999: II, 153), los cabalistas, teólogos, bibliotecarios, científicos, filósofos y detectives simbolizan concepciones dogmáticas del conocimiento. Cabe señalar que utilizamos aquí el término "dogmático" no tanto en el sentido corriente, que apunta al carácter impositivo o, incluso, fanático de una persona, sino en un sentido más amplio y descriptivo, que apunta a la actitud afirmativa y confiada de quien pretende conocer algo, ya sea en el sentido de que considera que puede llegar conocer algo, ya sea en el de que considera que ya conoce algo.

Para el escepticismo borgeano, todos estos personajes cometerían un pecado de bybris cognoscitivo que el autor, haciendo las veces del Yahvé del Libro de Job, se encargará de castigar. Así, los bibliotecarios de «La biblioteca de Babel» simbolizan la actitud dogmática de la modernidad, que con sus teorías filosóficas y científicas ha simplificado y empobrecido el mundo, impidiéndoles tener contacto con una realidad inconmensurable e irreductiblemente compleja. También «Funes el memorioso», con su prodigiosa memoria y capacidad perceptiva, y «El Aleph», que permite verlo todo desde todas las perspectivas, simbolizan las ingenuas pretensiones que tienen la ciencia y la filosofía moderna, en particular, y los hombres dogmáticos de todas las épocas, en general, de disponer y manipular la información suficiente para saber qué cosa es el infinito universo. En ambas ocasiones, el resultado es desastroso. De un 
https://doi.org/10.46744/bapl.201201.005

lado, Funes no puede pensar, del otro, Carlos Argentino Daneri utiliza el Aleph para perpetrar un poema de gusto dudoso.

En «Del rigor en la ciencia» serán los mapas los que simbolicen la necesaria simplificación que nuestros perceptos y conceptos realizan de la realidad, siempre infinitamente más rica y compleja que las desvaídas noticias que de ella nos llegan. En «Los teólogos», la pretensión de conocer la naturaleza de Dios es castigada con la revelación de la ignorancia acerca del propio ser, pues los dos teólogos que se han enfrentado en un cruento debate acerca de la naturaleza de la Trinidad, que ha acabado con uno de ellos en la hoguera, resultan ser la misma persona a los ojos de Dios. Algo semejante sucederá con el rabino de «El Golem», que, tras haber fracasado en sus pretensiones de crear un ser vivo pronunciando sobre un trozo de arcilla el tetragrammaton o «nombre de Dios», lamentará haber creado a un monstruo, sin percatarse que Dios lo mira de un modo semejante.

Otro símbolo epistemológico habitual en la obra de Borges son los detectives, que se nos aparecen como símbolo de la razón moderna triunfante, que debe ser humillada por un asesino que hace las veces de dios castigador. No en vano, tal y como recuerda Borges, en «De la alegoría a las novelas», para Poe «Dupin es la Razón» (Borges, 1999: II, 124), Sherlock Holmes simboliza «la razón triunfante» (Vázquez, 1981: 40) y los asesinos de los relatos policiales son, de algún modo, «una derivación [...] del inconcebible Dios de los teólogos» (Borges, 1999:II, 64).

Al examinar la obra de los autores aquí citados nos encontramos con que en la mayor parte de las ocasiones los símbolos epistemológicos tienen como objetivo criticar actitudes cognoscitivas dogmáticas, esto es, confiadas en nuestra capacidad para conocer. Ciertamente, como sugerimos más arriba, la reflexión acerca de los modos de conocimiento suele ir asociada al escepticismo, puesto que los autores dogmáticos no sienten la necesidad de reflexionar acerca del conocimiento, que dan por seguro. Es normal, pues, que el símbolo epistemológico suela aparecer en la obra de autores escépticos, como es el caso de Erasmo, Montaigne, 
Shakespeare, Cervantes, Stevenson, Chesterton, Borges, Vargas Llosa o Iwasaki.

Recordemos brevemente que el escepticismo considera que las pretensiones de conocimiento generan tanto una ansiedad innecesaria, que lleva a la infelicidad, como un furor afirmativo, que lleva al fanatismo. Con el objetivo de retirar ese obstáculo en la vía hacia la vida buena y la buena vida, que consideraban indiscernibles, el escepticismo busca convencer al hombre de la imposibilidad de todo conocimiento. Podemos distinguir, pues, dos momentos en la vía escéptica: uno destructivo o crítico, en el que se busca desesperar al hombre de toda pretensión de conocimiento, y otro constructivo o práctico, en el que se intenta elaborar una sensibilidad y un criterio que le permitan vivir satisfactoriamente una existencia desconectada de toda pretensión cognoscitiva.

\section{La medicina como símbolo epistemológico en Neguijón}

Una vez presentado el concepto de «símbolo epistemológico» y señalada su estrecha conexión con el escepticismo, podemos pasar a estudiar la medicina como símbolo epistemológico en la novela Neguijón, de Fernando Iwasaki. Empecemos señalando que el título de la novela hace referencia a una extravagante creencia médica del siglo XVII, que consideraba que en el interior de los dientes podía engendrarse un pequeño gusano que se alimentaba de ellos, consumiéndolos.

Uno de los personajes principales de la novela, Gregorio de Utrilla, es un sacamuelas obsesionado por hallar un neguijón. La búsqueda de este ser inexistente es equiparada con la búsqueda de otras entidades fantásticas que excitaron la imaginación de hombres que se extralimitaron en su deseo de conocer la realidad: «Así como algunos boticarios eminentes buscan los números áureos y las piedras filosofales -contestó el aprendiz desjarretando una muela-, yo solo busco al inmundo neguijón que anida entre la roña y las grietas de los dientes» (Iwasaki, 2005: 79).

Pero la serie no se detiene aquí. Podríamos añadir el tetragrammaton, el flogisto, la esencia, la divinidad, el cogito, el absoluto o la identidad, 
https://doi.org/10.46744/bapl.201201.005

entre otras infinitas quimeras tras las que los hombres dogmáticos se fatigan a sí mismos y fustigan a los demás.

Desde este punto de vista, el neguijón se nos revela como un símbolo epistemológico de toda pretensión de conocimiento, de todo desafuero cognoscitivo. Ciertamente, a un maestro de las armonías léxicas como Fernando Iwasaki no se le escapa que este "gusanillo», tal y como se lo designa en la definición del Diccionario de autoridades que sirve de epígrafe a la novela, designa de algún modo al «gusanillo» del que desea conocer lo que está más allá de sus posibilidades, provocando, como afirma el escepticismo, ansiedad y fanatismo.

Es constante a lo largo de toda la novela la idea de que la creencia en la existencia del neguijón causa un dolor superfluo y evitable en comparación con el dolor natural e inevitable que causan las caries. La novela se inicia con el tañido de una campana que anuncia la llegada de algo «infinitamente peor y más doloroso» que «la peste» o «el fuego», la llegada del sacamuelas Gregorio de Utrilla, cuya incansable búsqueda del neguijón lo lleva a multiplicar el dolor de sus pacientes (Iwasaki, 2005: 15).

Ciertamente, pinchar y requemar con alumbre y azufre las llagas para buscar la guarida del neguijón (Iwasaki, 2005: 72), sajar las mejillas y abrir los flemones con el objetivo de «sorprender al neguijón en la misma madriguera de la pus» (64) o arrancar varios dientes sanos por creer que el neguijón salta a otros dientes cuando se arranca aquel en el que se halla (50), supone aumentar inútilmente, en aras de una quimera, el dolor natural que provocan las meras caries. De ahí que uno de los personajes considere que los barberos «le habían descalabrado la boca con mayor estropicio que los gusanos» (50).

Poco después se nos informa de que el inquisidor Tortajada se escarba la dentadura con un mondadientes de plata y que a pesar de que esta actividad le provoca un dolor que «le traspasaba como el rayo», la esperanza de poder «empalar al neguijón que le perforaba los dientes», le lleva a seguir escarbando las caries, «picoteando feroz hasta caer desfallecido» (Iwasaki, 2005: 17). También el caballero Valenzuela «odiaba a los 
barberos», porque, tal y como se explica en el noveno capítulo de la novela, de pequeño «le limaron los dientes» por una peregrina creencia médica, «condenándole a padecer una dentadura quebradiza y desbaratada» (16). Por otra parte, el símbolo epistemológico del neguijón resuena con esa "pierna fantasma, que le dolía todavía más que el muñón» (15), del librero Linares, que también simboliza esa tendencia del ser humano a generar, fruto de sus desaforadas pretensiones de conocimiento, fantasías que acaban provocándole miedo y ansiedad.

Cabe tener en cuenta que la medicina de los siglos XVI y XVII constituía un cuerpo doctrinal altamente especulativo en el que las observaciones físicas eran interpretadas de acuerdo con un sistema de ideas previas, generadas a priori, y en ocasiones de forma totalmente fantasiosa (Cerveró, 1987: 36). Así como en el seno de la escolástica, la filosofía era esclava de la teología, en el seno de la práctica médica, la observación era esclava de la elucubración.

Ya en época grecolatina se produjo una crítica de esta concepción especulativa de la medicina. Filinos de Cos fundará, en 250 a.C., la medicina empírica, que conocerá su momento de máximo esplendor en el siglo II d.C., con Menodoto de Nicomedia, Herodoto de Tarso y Sexto Empírico, «llamada así por el papel principal que asignaba a la experiencia en el diagnóstico y el tratamiento de las enfermedades» (Verdan, 1971: 36). Dicha doctrina, considerada uno de momentos más importantes de la historia del pensamiento escéptico -como prueba el hecho de que Sexto Empírico, autor de la más importante obra escéptica, los Esbozos pirrónicos, formase parte de ella-, se oponía a los médicos «especulativos», «doctrinarios» o «dogmáticos», que, siguiendo las enseñanzas de Hipócrates, buscaban desentrañar las «causas profundas» de las enfermedades, formulando en ocasiones hipótesis totalmente gratuitas. Los empíricos consideraban que este tipo de pensamiento especulativo daba lugar a teorías fantasiosas e incontrastables que podían dar lugar a prácticas perjudiciales para los enfermos, que es precisamente lo que hace el sacamuelas Gregorio de Utrilla en la novela que nos ocupa. Así, para los médicos empíricos la medicina no debe intentar desentrañar «si las enfermedades provienen 
https://doi.org/10.46744/bapl.201201.005

de un desarreglo de los cuatro humores fundamentales o de una insuficiencia del pneuma», sino, simplemente, "observar los signos aparentes, las manifestaciones exteriores de las enfermedades, los síntomas, sin tratar de buscar el porqué, el origen oscuro» (Verdan, 1971: 36). Según indica Victor Brochard, uno de los más importantes historiadores del escepticismo, los médicos empíricos rechazaron el dogmatismo, como luego los positivistas rechazaron la metafísica (1981: 310).

Por otra parte, la medicina de los siglos XVI y XVII, además de ser altamente especulativa, incluía tanto prácticas como las de los médicos, cirujanos o apotecarios, que empezaban a adoptar unos métodos propiamente científicos, como un cúmulo de oficios como los de barbero, sangrador o herbolario, que representaban «un residuo de actividades pragmáticas medievales» (Cerveró, 1987: 246) con una estrecha conexión con el mundo de la magia (López Piñero, 1979: 47-58).

Si bien es cierto que en la Europa del Renacimiento tuvo lugar la llamada revolución paracélsica de la medicina, que supuso un cierto giro empírico, y, por lo tanto, escéptico y antiespeculativo, de la disciplina, su desarrollo peninsular se vio truncado por el «cordón sanitario» impuesto por la Contrarreforma, que cerró las fronteras a los científicos que querían estudiar en el extranjero y prohibió la difusión de ideas «foráneas», así como por la desaparición de la comunidad judía y la crisis económica de la última parte del siglo XVI (López Piñero, 1976: passim y Cerveró, 1987: 25). En varios pasajes de Neguijón se hace referencia al carácter aislado y arcaico de la medicina peninsular: «Linares sabía que en Francia se trataban las amputaciones con emplastos de yema de huevo, aceite de rosas y trementina, pero eso lo había leído en los libros prohibidos» (Iwasaki, 2005: 32).

Evidentemente, el alcance simbólico del neguijón no se reduce a la medicina especulativa o elucubrativa barroca, sino que se aplica a todo tipo de quimera dogmática, científica, teológica o filosófica; pasada, presente y futura; peninsular, europea o americana. Ciertamente, no parece casual que las principales víctimas de esa fantasía odontológica que es el neguijón sean un inquisidor, un noble y un librero, cuyas 
respectivas quimeras teológicas, nobiliarias y eruditas también siembran el mundo de dolores y angustias inútiles y evitables.

No es casual que la medicina especulativa barroca, simbolizada por el neguijón, sea equiparada a la religión dogmática, que también sacrifica, en aras de un más allá elucubrado, la existencia, cariada, pero más o menos soportable, de los hombres reales. Así, los pacientes del barbero Utrilla son presentados como creyentes - «la devota resignación del doliente» (Iwasaki, 2005: 19), «Los cofrades del dolor de muelas» (27)-; sus operaciones son presentadas como una «liturgia del dolor» (29); el tiempo de las intervenciones es calculado en credos - «Diez credos más tarde...» (43), «¿Cuántos credos tardó en aserrarla?» (133)- ; se compara, con el objetivo de desvalorizarlo, el dolor de los pacientes con el de la pasión de Cristo - «Utrilla miraba a los ojos suplicantes del enfermo y le susurraba -como si fuera la absolución o una confidencia- que Nuestro Señor Jesucristo había padecido mucho más en la cruz.» (19)-; y hasta el barbero llega a predicar mientras oficia su ritual odontológico -«Dios, en su infinita sabiduría - prosiguió Utrilla enfervorizado-, dispuso que en las dentaduras anidara el neguijón, para que el dolor de muelas nos acompañara por siempre como advertencia del eterno tormento de la muerte» (28).

También las constantes armonías y referencias al Quijote que pueblan Neguijón parecen apuntar a que uno de los objetivos principales de Fernando Iwasaki es reflexionar acerca de nuestros modos de conocimiento, para luego criticar todo tipo de dogmatismo. No se trata solo, claro está, de que en el segundo epígrafe de Neguijón oigamos el nombre de esa fantasía odontológica que es el «neguijón» en boca del fantasioso don Quijote o de las numerosas referencias al Examen de ingenios de Huarte de San Juan, hito de la tradición escéptica y una de las fuentes principales de Cervantes.

Como dijimos más arriba, don Quijote constituye, de algún modo, «una parodia del filósofo dogmático» (Ihrie, 1982: 31), que se caracterizaría por fundar su verdad en la lectura antes que en la experiencia o el razonamiento - por leer demasiado «se le secó el celebro, de manera que 
vino a perder el juicio» (I, i)-; por ignorar o distorsionar la información aportada por sus sentidos con el objetivo de adaptarla a sus ideas preconcebidas - «como a nuestro aventurero todo cuanto pensaba, veía o imaginaba le parecía ser hecho y pasar al modo de lo que había leído, luego que vio la venta se le representó que era un castillo» (I, ii), «esto se te hiciera cierto si hubieras leído tantas historias como yo» (I, $\mathrm{x}$ )-; y por poseer una visión esencialista de la realidad, que tiende a traducirse en una rígida clasificación de las cosas y de las personas, que defenderá celosa e, incluso, violentamente, sin condescender jamás al diálogo - «Confesad, malandrines, así a carga cerrada, que es verdad lo que yo aquí he publicado; si no, conmigo sois en batalla» (II, lviii)-.

También los personajes de Neguijón son hombres dogmáticos que creen amasar certezas, cuando lo único que poseen son fantasías, como prueba el hecho de que buena parte de los términos y conceptos médicos, teológicos o filosóficos del libro sean obsoletos. Este hecho es subrayado irónicamente por el narrador, que nos los presenta seguros de sus fantasiosas y efímeras verdades: «[Gregorio de Utrilla] distinguió el olor inconfundible de las muelas agusanadas» (Iwasaki, 2005: 36); «El librero Linares sabía que los gusanos nacían de la humedad y de la corrupción» (17); «todo el mundo estaba persuadido de que aquella hinchazón era consecuencia de la lectura exagerada» (44). La mise en abîme es inevitable: ¿no serán también nuestras seguridades actuales objeto de burla para futuros narradores y lectores?

Ciertamente, los personajes de Neguijón cumplen con la caracterización del dogmático señalada más arriba. El barbero Gregorio de Utrilla antepone sus lecturas a la experiencia, pues a pesar de llevar tras varias décadas arrancando muelas sin haber encontrado jamás un neguijón, prefiere seguir creyendo a las autoridades médicas que afirman su existencia, que, por otra parte, tampoco vieron jamás el gusano en cuestión:

En la Summa y Examen de Chirurgia del portugués Antonio Pérez, Utrilla había leído que los neguijones podían ser atrapados si la muela era reventada con presteza, pero el cirujano mayor de la 
Armada Invencible jamás prendió a un neguijón ni dio noticias de su forma, tamaño y color (Iwasaki, 2005: 50).

También el librero Linares, del que se nos dice que vivía «en el trasmundo de los libros» (Iwasaki, 2005: 57), lo conoce todo de la esgrima y de la lucha, si bien «todo ello lo había aprendido leyendo en su tienda de la calle Borceguinería» (22), tras lo cual el narrador exclama, «iAy, sus libros!» (23).

Tanto es así que en los capítulos 8 y 12 de la novela se realizará un escrutinio de una biblioteca formada, en su mayoría, por libros «científicos», que, como indica el autor en el apéndice (Iwasaki, 2005: 157), representan el saber del siglo XVII, y que no hace más que repetir el escrutinio realizado por la historia, que la ha desestimado en su práctica totalidad. En la línea del escepticismo borgeano, Fernando Iwasaki considera que no solo la literatura fantástica, en general, y las novelas de caballería, en particular, forman parte del género fantástico, sino también la filosofía, la historia, la ciencia y, en general, cualquier tipo de ensayo cognoscitivo: «Alonso Quijano enloqueció por leer libros de caballerías, aunque habría terminado igual de loco si hubiera leído tratados de mística o de medicina» (157).

Por otra parte, la actitud dogmática de los personajes de Neguijón también se traduce en una rígida clasificación de la realidad que tienden a defender de forma celosa e, incluso, violenta, como también le sucedía a don Quijote. Así, los barberos y cirujanos que aparecen en la novela no se inmutan ante el dolor que causan en los demás, que siempre consideran justificado por sus conocimientos; doña Luisa de Melgarejo parece estar dispuesta a dejarse arrancar todos los dientes para demostrar su santidad; el caballero Valenzuela vive obsesionado por su nombre y origen; y la alargada sombra de la Inquisición planea sobre toda la obra.

Por si esto no fuera suficiente, el hecho de que toda la novela gire en torno a la figura de un barbero la hermana íntimamente con el Quijote, uno de cuyos episodios más conocidos y más significativos desde el punto de vista de la reflexión epistemológica es el de la bacía 
de barbero. Señalemos que en dicho episodio Cervantes no solo se burla de los barberos -como tampoco en su novela se burla solo de las novelas de caballerías-, sino de todo tipo de conocimiento dogmático. Tengamos en cuenta que tras el Concilio de Trento se volvió muy peligroso criticar a los teólogos dogmáticos, de modo que muchos autores optaron por criticarlos indirectamente, a través de la tradición burlesca que cargaba contra la medicina, que era, como vimos, una actividad prácticamente tan especulativa como la teología. No es extraño, pues, que la crítica a la medicina como símbolo epistemológico del dogmatismo también haya sido frecuentada por otros escépticos como Montaigne, Shakespeare, Quevedo o Molière.

Sin embargo, mientras que en el Quijote, el protagonista aprende a comprobar la fiabilidad de lo que las apariencias parecen sugerirle -«Así como vi este carro imaginé que alguna grande aventura se me ofrecía; y ahora digo que es menester tocar las apariencias con la mano para dar lugar al desengaño». (II, xi)-, llegando a mostrarse cada vez más prudente y circunspecto - «Todo podría ser -respondió don Quijote-; pero yo haré lo que me aconsejas, puesto que me ha de quedar un no sé qué de escrúpulo» (II, xxv)-, en Neguijón los personajes no evolucionan, sino que se quedan encerrados en su dogmatismo inicial. Esto expresa, quizás, cierto pesimismo en lo que respecta a las posibilidades de curación del dogmatismo español e hispanoamericano, que ha ido pasando su testigo desde la España contrarreformista hasta nuestros días.

De este modo, el neguijón no solo sería el «gusano barroco español» del que surgirá, como sugiere felizmente Iwasaki en el epílogo de su novela, «la mariposa hispanoamericana del realismo mágico», sino también el nombre de un mismo destino filosófico y político dogmático e, incluso, fanático.

Quizás el único personaje que ofrece cierta esperanza epistemológica es Bernabillo, apodado «El de las plantas», que desea escribir «una monumental Historia del Nuevo Mundo» (Iwasaki, 2005: 75), que debía incluir un catálogo de las hierbas medicinales americanas. La metodología utilizada por Bernabillo, que será ayudado por el caballero 


\section{https://doi.org/10.46744/bapl.201201.005}

Valenzuela, es puramente empírica, puesto que consiste en «probar todos los mejunjes y cocimientos que Bernabillo preparaba meticulosamente para añadir nuevas plantas a su frondoso catastro de hojas, frutos, raíces, hierbas y semillas de las Indias Occidentales» (76). Tras varias probaturas que le harán sufrir diarreas, estreñimientos o vómitos, Bernabillo logrará descubrir «que la achuma menguaba el ardor de la orina, que el jugo del mocomoco en ayunos deshacía los cálculos en la vejiga» (77).

Estos descubrimientos son el premio por haber usado una metodología empírica, radicalmente contraria a las elucubraciones de la medicina especulativa, simbolizada por el barbero Gregorio de Utrilla y su delirante búsqueda del neguijón. Cabe ver, quizás, un homenaje a ese avatar del escepticismo empírico que fue el positivismo, y que tanta importancia tuvo en Latinoamérica, no solo como instrumento de deslatinización y sajonización (Zea, 1980), sino también como un ensayo de cura del dogmatismo colonial mediante una apuesta por un fenomenismo radical de corte empírico. 


\section{BIBLIOGRAFÍA}

ALAZRAKI, Jaime. La prosa narrativa de Jorge Luis Borges. Madrid, Gredos, 1983.

BELL, Millicent. Shakespeare's Tragic Skepticism. Yale University Press, New Haven, 2002.

BORGES, Jorge Luis. Obras Completas. Emecé, Barcelona, 1999.

BROCHARD, Victor. Les sceptiques grecs. Librairie Philosophique J. Vrin, Paris, 1981.

CASTANY PRADO, Bernat. El escepticismo en la obra de Jorge Luis Borges. Cuadernos de América Sin Nombre, Alicante, 2012.

CERVANTES, Miguel. Don Quijote de la Mancha. Francisco Rico (ed.), Crítica, Barcelona, 1998.

CERVERÓ, Lluis. La medicina en la literatura valenciana del segle XVI. Tres i Quatre, Valencia, 1987.

IHRIE, Maureen. Skepticism in Cervantes. Tamesis Books Limited, London, 1982.

IWASAKI, Fernando. Neguijón. Alfaguara, Madrid, 2005.

LÓPEZ PIÑERO, J. M. Medicina moderna y sociedad española. Siglos XVI-XIX, Cátedra e Instituto de Historia de la Medicina, Valencia, 1976.

LÓPEZ PIÑERO, J. M. Ciencia y técnica en la sociedad española de los siglos XVI y XVII. Labor, Barcelona, 1979.

OSTERC, Lúdovik. "Cervantes y la medicina», en Verba hispánica, VI, 1996, págs. 17-22. 
https://doi.org/10.46744/bapl.201201.005

VÁZQUEZ, Nélida E. Borges: La humillación de ser hombre. Febra Editores, Buenos Aires, 1981.

VERDAN, André. Le scepticisme philosophique. Bordas, Paris, 1971.

VILLACIÁN VICEDO, María José y Villamil Cajoto, Iago. «Cervantes, El Quijote y la medicina», en Revista Médica de Chile, 133, 2005, pp. 1258-1260.

ZEA, Leopoldo. "Prólogo" a VV.AA., Pensamiento positivista latinoamericano, antología y prólogo de Leopoldo Zea, Biblioteca Ayacucho, Caracas, 1980.

\section{Correspondencia:}

\section{Bernat Castany Prado}

Docente de Literatura Hispanoamericana y Estudios Literarios en la Universidad de Barcelona.

Correo electrónico: bcastany@ub.edu 